\title{
The Performance Evaluation of China Railway Corporation Modern Logistics Based on Combination Weighting Method and TOPSIS Method
}

\author{
Bin Feng ${ }^{1, a^{*}}$, Si Ping Qin ${ }^{2, b}$ \\ ${ }^{1}$ Beijing Haidian District Shangyuan Village No. 3, china \\ ${ }^{2}$ Beijing Haidian District Shangyuan Village No. 3, china \\ a12120971@bjtu.edu.cn, bspqin@bjtu.edu.cn
}

Keywords: Performance evaluation; Combination weighting method; TOPSIS method; China Railway Corporation; Modern logistics

\begin{abstract}
This paper constructs the China Railway Corporation modern logistics performance evaluation index system from financial, customer, internal processes and learning and growth four dimensions based on the current situation, and constructs the performance evaluation model based on combination weighting method and TOPSIS method. Then use the modern logistics performance from 2008 to 2012 as an example to prove the validity of the model.
\end{abstract}

\section{Introduction}

Ministry of railways issued 《opinions on the extension of railway cargo transportation service chain, accelerate the development of modern logistics railway》 in 2012. Ministry of railways's government functions and corporate functions were separated, China Railway Corporation (abbreviation CRC in the following part) is established as the main part of market operation, which paved the way for railway modern logistics strategy. Supports of railway modern logistics for community economic development function are also gradually improving. However, the assessment of CRC's modern logistics management performance is still blank. Railway modern logistics development outcomes remain to be tested.

Currently, the assessment of railway enterprises are mainly concentrated in two directions: Firstly, the assessment of the Railway Bureau, Station Segment [1] and so on; secondly, the assessment of the performance of a single operational performance[2][3] and so on. No one has a comprehensive and systematic study of CRC modern logistics performance problems in recent years.

\section{Characteristics of CRM Modern Logistics Performance Evaluation}

CRC's management is directly attributabled to the State Department,which is difficult to determine the assessment body. CRC is different from other central enterprises. In general, State-owned Assets Management Committee manages central enterprise, However, State Council manages CRC and National Railroad Bureau supervise CRC. Its exceptional level leads to the lack of monitoring and evaluation.

CRM has a natural monopoly, which is difficult to choose the contrast objects. Because of China's special conditions, Centralized scheduling is always used by rail system. CRM worked as the only one railway enterprises, There is no analogous enterprises in china, and foreign railway enterprises business experience is only for reference.

CRM has nonprofit transportation duties, which is difficult to appraisal assessment results. CRM bears on the task of national economy and strategic materials transportation, subsidy mechanism has not yet formed now, Therefore, the evaluation results is difficult to measure. 


\section{CRM Modern Logistics Performance Evaluation Model Based on Combination Weighting Method and TOPSIS Method}

The method of modern logistics performance evaluation have DEA[1], principal component analysis[4], TOPSIS [5] and so on. This article plans to use a combination of empowerment and TOPSIS method to assess performance of CRM. Combination weighting method is combined with subjective and objective weighting method. Subjective weighting method chosen analogy analysis, which is close to large state-owned enterprises current situation; and objective weighting method choose entropy method in order to reduce the subjectivity of subjective weighting.Topsis method has the advantage of clear thinking, calculating convenient, flexible application,and can avoid the blindness of selecting evaluation criteria. Specifically, the model can be divided into seven steps.

Step 1: Establish performance evaluation index system;

Step 2: Collect and process evaluation Index data;

Assuming there are $m$ objects to be evaluated, $n$ evaluation Index. According to information gathered, we can endow specific indicators for each evaluation index values and listed in the initial matrix. This is the original data matrix $X=\left(x_{i j}\right)_{m} \times{ }_{n}$. Then index data are handled dimen-sionlessly and consistently. The result is normalized matrix $V=\left(v_{i j}\right)_{m} \times n$.

Step 3: Use the method of analogy analysis- entropy to determine the index weight; Formula is shown in Eq.1.

$$
W=\left(w_{1}, w_{2}, \ldots w_{n}\right)=(1-t) W_{A n}+t W_{E n}
$$

In the formula above: $W$ - Integrated weight vector determined by the method of analogy analysisentropy; $W_{A n}-$ Weight vector determined by the method of analogy analysis; $W_{E n}$-Weight vector determined by the method of entropy; $t$-Correction coefficient, it can be value $t=\frac{n}{n-1} R_{E n}$, $R_{E n}=\frac{2}{n}\left(1 P_{1}+2 P_{2}+\cdots+n P_{n}\right)-\frac{n+1}{n}, \quad P_{1}, P_{2}, \ldots P_{\mathrm{n}}$ is the index weight vector $W_{E n}$ sorted from small to large. The use of correction coefficient $t$ can correct the subjective to ensure the rationality of index weight determination.

Step 4: Construct weighted normalized matrix $R$; Formula is shown in Eq.2.

$$
R=\left(r_{i j}\right)_{m \times n}=W \times V=\left[\begin{array}{cccc}
v_{11} & v_{12} & \cdots & v_{1 n} \\
v_{21} & v_{22} & \cdots & v_{2 n} \\
\cdots & \cdots & \cdots & \cdots \\
v_{m 1} & v_{m 2} & \cdots & v_{m n}
\end{array}\right]
$$

Step 5: Determine the index of the positive ideal solutions $S_{j}^{+}$and negative ideal solutions $S_{j}^{-}$;

The element in positive ideal solutions is the optimal value of each appraisal object index, The element in negative ideal solutions is the inferior value of each appraisal object index. Because after the matrix $R$ index weighted normalization processing are very large index, the $S_{j}^{+}$and $S_{j}^{-}$can be shown in Eq.3 and Eq.4.

$$
S_{j}^{+}=\max _{1 \leq i \leq m}\left\{r_{i j}\right\}, \quad S_{j}^{-}=\min _{1 \leq i \leq m}\left\{r_{i j}\right\} \quad j=1,2, \cdots, n
$$

Step 6: Calculate the euclidean space distance from all objects to be evaluated to the positive ideal solution and negative ideal solution; Formula is shown in Eq.5 and Eq.6.

$$
S d_{i}^{+}=\sqrt{\sum_{j=1}^{n}\left(S_{j}^{+}-r_{i j}\right)^{2}}, \quad S d_{i}^{-}=\sqrt{\sum_{j=1}^{n}\left(S_{j}^{-}-r_{i j}\right)^{2}} \quad i=1,2, \cdots, m
$$

Step 7: Calculate the relative closeness degree $C_{i}$ between all objects to be evaluated and the positive ideal solution; Formula is shown in Eq.7. 


$$
C_{i}=\frac{S d_{i}^{-}}{S d_{i}^{+}+S d_{i}^{-}} \quad i=1,2, \cdots, m
$$

According to the relative closeness to the ideal size, we can sort the object of assessment. If the relative closeness degree $C_{i}$ is big, the evaluation objects is more closer to the positive ideal solution and it will be rank forefront; if the relative closeness degree $C_{i}$ is small, it will be rank at the last.

\section{An Empirical Study on the Evaluation of Chinese Railway Modern Logistics Performance}

Step 1: Establish performance evaluation index system. Performance evaluation index system is constructed based on BSC from financial, customer, internal processes and learning and growth four dimensions. Performance evaluation index system is shown in Table.1.

Table 1 Performance evaluation index system

\begin{tabular}{|c|c|c|}
\hline First grade & Second grade & Approach of achieving \\
\hline \multirow{5}{*}{ Finance } & Transportation profit growth rate & $\begin{array}{c}\text { Statistical communique } \\
\text { Bond prospectus } \\
\end{array}$ \\
\hline & Shipping income growth rate & $\begin{array}{c}\text { Statistical communique } \\
\text { Bond prospectus }\end{array}$ \\
\hline & White goods freight income growth rate & Statistical communique \\
\hline & Value-added service income growth rate & No data \\
\hline & Total assets & $\begin{array}{c}\text { Statistical communique } \\
\text { Bond prospectus }\end{array}$ \\
\hline \multirow[b]{2}{*}{ Customers } & Customer retention & No data \\
\hline & Freight volume growth rate & $\begin{array}{c}\text { Statistical communique } \\
\text { Bond prospectus }\end{array}$ \\
\hline \multirow{3}{*}{$\begin{array}{c}\text { Internal } \\
\text { business } \\
\text { procedures }\end{array}$} & Wagon Turnround Time & Statistical communique \\
\hline & Damage or loss rate & Score by expert \\
\hline & Rate of complaints & Score by expert \\
\hline $\begin{array}{l}\text { Learning and } \\
\text { growth }\end{array}$ & Rate of employee turnover & $\begin{array}{c}\text { Statistical communique } \\
\text { Bond prospectus }\end{array}$ \\
\hline
\end{tabular}

Step 2: Collecting primary data. Most of the data is from Statistical communique and Bond prospectus. However, some data is hard to collect, and some data isn't counted now. Therefore, some data is scored by expert, such as damage or loss rate and rate of complaints. The expert assumes that damage or loss rate and rate of complaints improve continually. The paper assume the data that hasn't be counted is 1 in order not to affect the results.

Table 2 Performance evaluation index system primary data

\begin{tabular}{c|c|c|c|c|c|c}
\hline Second grade & $\mathbf{2 0 0 7}$ & $\mathbf{2 0 0 8}$ & $\mathbf{2 0 0 9}$ & $\mathbf{2 0 1 0}$ & $\mathbf{2 0 1 1}$ & $\mathbf{2 0 1 2}$ \\
\hline $\begin{array}{c}\text { Transportation } \\
\text { profit[billion yuan] }\end{array}$ & 727.22 & 499.99 & 626.98 & 655.55 & 680.87 & 663.99 \\
\hline $\begin{array}{c}\text { Shipping income } \\
\text { [billion yuan] }\end{array}$ & 1392.50 & 1502.07 & 1647.08 & 1997.66 & 2211.10 & 2330.96 \\
\hline $\begin{array}{c}\text { White goods } \\
\text { freight income } \\
\text { [billion yuan] }\end{array}$ & 304.78 & 310.21 & 316.88 & 378.27 & 435.77 & 413.41 \\
\hline $\begin{array}{c}\text { Value-added } \\
\text { service income } \\
\text { [billion yuan] }\end{array}$ & 1 & 1 & 1 & 1 & 1 & 1 \\
\hline Total assets & 15522.9 & 18553.2 & 24566.4 & 32937.4 & 39796.4 & 44877.0 \\
\hline
\end{tabular}




\begin{tabular}{c|c|c|c|c|c|c}
\hline [billion yuan] & & & & & \\
\hline $\begin{array}{c}\text { Customer } \\
\text { retention[\%] }\end{array}$ & 1 & 1 & 1 & 1 & 1 & 1 \\
\hline Freight volume[t] & 262400 & 275243 & 2775712 & 309541 & 329535 & 323560 \\
\hline $\begin{array}{c}\text { Wagon Turnround } \\
\text { Time[d] }\end{array}$ & 4.76 & 4.73 & 4.68 & 4.48 & 4.45 & 4.68 \\
\hline $\begin{array}{c}\text { Damage or loss } \\
\text { rate[\%] }\end{array}$ & 0.05 & 0.04 & 0.03 & 0.02 & 0.01 & 0.01 \\
\hline $\begin{array}{c}\text { Rate of } \\
\text { complaints[\%] }\end{array}$ & 0.05 & 0.04 & 0.03 & 0.02 & 0.01 & 0.01 \\
\hline Employee [p] & 1741029 & 1732909 & 1850147 & 1756385 & 1761542 & 1793267 \\
\hline
\end{tabular}

Step 3: Use the method of analogy analysis- entropy to determine the index weight. This paper analogy the Weight in the 《Performance evaluation method of Railway Bureau》 and 《Performance appraisal method of central enterprises $\rangle$ to obtain $W_{A n}$, then calculate $W_{E n}$ and $W$.

$$
\begin{gathered}
W_{A n}=(0.350,0.070,0.030,0.050,0.100,0.050,0.050,0.050,0.100,0.050,0.100) ; \\
W_{A n}=(0.081,0.138,0.117,0.000,0.110,0.000,0.109,0.100,0.153,0.100,0.091) ; \\
W=(0.025,0.086,0.051,0.038,0.103,0.038,0.064,0.062,0.113,0.062,0.098) .
\end{gathered}
$$

Step 4: Use TOPSIS to calculate the final result. The final result is shown in Table.3.

Table 3 performance evaluation index system

\begin{tabular}{l|l|l|l|l|l}
\hline Year & $\mathbf{2 0 0 8}$ & $\mathbf{2 0 0 9}$ & $\mathbf{2 0 1 0}$ & $\mathbf{2 0 1 1}$ & $\mathbf{2 0 1 2}$ \\
\hline Score & 0.391 & 0.603 & 0.570 & 0.492 & 0.528 \\
\hline
\end{tabular}

Through the above analysis, the overall ranking is as follow:

$P(2009)>P(2010)>P(2012)>P(2010)>P(2008)$.

\section{Conclusion}

Because of the financial crisis,CRM business performance has a sharp decline in 2008, so it ranks last. The chinese government unveiled its stimulus package in november,2008, so the performance is very good in 2009. with the weakening of economic stimulus, it continued to decline from 2010 to 2012. However, the railway began to vigorously develop modern logistics industry since 2012 years, so the performance in 2012 is better than 2011. Therefore, this model can better reflect the actual performance of railway.

It is one such necessary path for CRM to implemente the strategy of modern logistics and actively expand the high value goods market.

\section{References}

[1] E.F. Zhang, The design and implementation of the performance appraisal system for railway stations and depots (MS., Shanghai Jiao Tong University, China 2012), p.44.

[2] Z. Li, Q. Li and G.F, Wang. Journal of Systems Management, (2006) No.2, p.10-14

[3] Y. Teng, Journal of Railway Science and Engineering, (2010) No.5, p. 113-117.

[4] S.Z. Zhang and C.N. Zhang, Journal of Chang An University: Social Science, (2013) No.1, p. 33-37.

[5] S.Q. Xu, Logistics Technology, (2014) No.11, p:12-14 
[6] J. Li and D.X. Lei, Railway Freight, (2007) No.4, p. 20-24

[7] Y.B. Li, Shan Dong Science, (2014) No.1, p. 33-35

[8] T.S. Chen, Journal of Beijing Jiaotong University: Social Science, (2009) No.3, p. 51-55.

[9] W.L. Yan, Chinese Human Resources Development, (2006) No.12, p. 14-18

[10]L. Liu, Study on railway operating performance in China based on DEA(MS., Southwest Jiao Tong University, China 2008), p.36. 